EESTI NSV TEADUSTE AKADEEMIA TOIMETISED. V KOIDE BIOLOOGILINE SEERIA. 1956, NR. 4

ИЗВЕСТИЯ АКАДЕМИИ НАУК ЭСТОНСКОЙ ССР. ТОМ V СЕРИЯ БИОЛОГИЧЕСКАЯ. 1956. № 4

\title{
О ВЛИЯНИИ ВДЫХАНИЯ СЛАНЦЕВОЙ ПЫЛИ НА ТЕЧЕНИЕ ЭКСПЕРИМЕНТАЛЬНОГО ТУБЕРКУЛЕЗА
}

\author{
В. А. КЮнг, \\ кандидат медицинских наук
}

п. А. Боговскии,

кандидат медицинских наук

\section{X. Я. ЯHEC}

Важное место среди вопросов гигиены труда в сланцевой промышленности занимает изучение вредного для здоровья влияния пыли, возникающей в процессе добычи и переработки горючего сланца. Влияние сланцевой пыли на возникновение и течение туберкулеза легких не выяснено, к тому же вопрос о взаимосвязи запыления легких и туберкулеза является вообще довольно сложным и мало изученным разделом профессиональной патологин.

Данные о заболеваемости рабочих сланцевой промышленности туберкулезом весьма скудны и не позволяют сделать выводов о связи между вдыханием промышленной пыли и туберкулезным процессом. Нашей целью было выяснение влияния вдыхания сланцевой пыли на течение экспериментального туберкулеза у морских свинок. Вопрос о влиянии производственной пыли и вызванных ею пневмокониозов на возникновение и течение туберкулеза легких имеет наряду с теоретическим интересом и большое практическое значение.

Значение пылевого фактора в этиологии и патогенезе туберкулеза легких оценивали до последнего времени различно. Литература о характере взаимоотношений пневмокониозов и туберкулеза легких содержит различные противоречивые данные.

Бо́льшая часть авторов считает, что запыление легких способствует развитию туберкулеза. Уже в начальном периоде развития медицины, как отмечает Н. А. Вигдорчик $\left({ }^{1}\right)$, врачи того времени рассматривали профессиональное запыление легких как фактор, способствующий возникновению туберкулеза и неблагоприятно влияющий на его течение. В прошлом, когда данных о пылевом поражении легких было недостаточно, больных с запылением легких считали туберкулезными больными. Понятия пневмокониоза и силикоза, определяющие соответствующие болезни, возникающие вследствие запыления легких, получили общее признание только в конце прошлого столетия.

Так как туберкулез легких особенно часто находили у больных силикозом, то некоторые авторы, как Икерт (Ickert), Поликар (Policard) и др., отрицали наличие самостоятельного силикоза (Пик $\left({ }^{10}\right)$, Серов $\left({ }^{12}\right)$ ). В силикозе видели особую форму туберкулеза, которая возникает при содействии пылевого фактора. Силикотический узелок считали туберкулез- 
ной гранулемой. Некоторые советские авторы, как Д. А. Карпиловский и Л. Л. Гольст, также принимали далеко развившийся силикоз за кониотуберкулез (Генкин $\left.\left({ }^{2}\right)\right)$.

Однако, как показали клинико-рентгенологические и патоморфологические исследования И. И. Мошковского $\left({ }^{\circ}\right)$, Ф. И. Пожариского $\left({ }^{11}\right)$, П. П. Движкова $\left({ }^{5}\right)$, С. Ф. Серова $\left({ }^{12}\right)$ и других, силикоз, несмотря на частое осложнение туберкулезом, является самостоятельной нозологической единицей со своей определенной этиологией и картиной заболевания. Возможность развития силикотического процесса без участия туберкулезной инфекции доказана также и многими экспериментальными исследованиями.

Менее ясным является взаимное влияние туберкулеза и пневмокониоза при их сочетании. В отличие от широко распространенного взгляда, что при пневмокониозе туберкулез протекает для больных неблагоприятно, ряд авторов во главе с немецким патологом Рессле (Rössle) стали на диаметрально противоположную точку зрения, утверждая, что силикотические изменения задерживают развитие туберкулеза легких (Генкин $\left({ }^{2}\right)$, Серов $\left({ }^{12}\right)$ и др.). Предполагалось, что блокада лимфатических путей пылевыми клетками и фиброзные изменения ткани легких препятствуют распространению туберкулезной инфекции. Считали также, что пылевой фиброз способствует инкапсуляции туберкулезных очагов и их рубщеванию. Рессле и другие, считающие пылевой пневмосклероз антагонистом туберкулезного процесса, рекомендовали применять соединения стилиция для лечения туберкулеза легких. Некоторые авторы, приписывающие противотуберкулезные защитные функции прежде всего угольной пыли, советовали направлять больных с начинающимся туберкулезом для излечения на работу в угольные шахты.

Делались попытки доказать полезность угольной пыли и статистическими данными, которые указывали на незначительную заболеваемость туберкулезом углекопов. Однако, на основании своих обширных клиникорентгенологических исследований И. И. Мошковский $\left({ }^{9}\right)$ показал, что нельзя говорить об охраняющих здоровье условиях труда в угольных шахтах только на основании односторонних статистических данных, так как в состав углекопов попадают путем подбора более сильные и здоровые рабочие. И. И. Мошковский не нашел подтверждения мнению, что кониотуберкулез у углекопов протекает более доброкачественно, чем обычный туберкулез легких.

В настоящее время имеются убедительные доказательства того, что пылевой пневмосклероз не оказывает защитного влияния от туберкулеза. Многочисленными клиническими и экспериментальными исследованиями доказано неблагоприятное влияние кварцсодержащей пыли на течение туберкулезного процесса. Установлено, что длительное вдыхание производственной пыли, содержащей значительное количество кварца, способствует возникновению и прогрессированию туберкулеза.

По статистическим данным частота туберкулеза легких возрастает параллельно тяжести силикотического процесса. Так, например, по C. M. Генкину $\left({ }^{2}\right)$ в золотом руднике туберкулез был обнаружен у $11 \%$ больных силикозом I стадии, у $20 \%$ больных силикозом II стадии и у $80 \%$ больных силикозом III стадии. Имеются также данные, говорящие о зависимости между тяжестью силикотического и туберкулезного процессов. При далеко зашедшем силикотическом процессе описаны более тяжелые формы туберкулеза (Серов $\left({ }^{\mathbf{1 2}}\right)$, Бэме (Вӧhmе) $\left({ }^{15}\right)$ и др.).

Для выяснения вопроса о взаимовлиянии запыления легких и туберкулеза произведены также экспериментальные работы. По данным многих авторов, у подопытных животных с экспериментальным силикозом 
туберкулез протекает в более тяжелой форме, чем у контрольных животных. М. К. Даль $\left(^{+}\right)$отмечал, что у тех кроликов, которые до инфицирования подвергались более длительному запылению кварцевой пылью, генерализация бывает более обширной и туберкулез протекает в более тяжелой форме. Арнольди и Еттен показали, что угольная пыль также способствует развитию туберкулеза у подопытных животных (Мошковский $\left.\left({ }^{2}\right)\right)$.

Гарднер (Gardner) производил сравнительные опыты для выяснения влияния вдыхания различных видов пыли на экспериментальный туберкулез (Соркин $\left.\left({ }^{15}\right)\right)$. Он установил, что кварцевая, гранитная и карборундовая пыль вызывают прогрессирование туберкулезного процесса и рассеивание очагов. У морских свинок, вдыхавших мраморную, асбестовую или каменноугольную пыль, прогрессирования туберкулеза не наблюдалось.

По данным Еттена и Кортмана (Jötten, Kortmann) $\left({ }^{16}\right)$, табачная и цементная пыль влияют незначительно на течение туберкулеза у подопытных животных. По наблюдениям тех же авторов, пыль глинистого сланца гораздо больше способствует развитию туберкулеза. Бианки (Bianchi) $\left({ }^{14}\right)$ инфицировал туберкулезом кроликов, которые предварительно в течение ряда месяцев вдыхали мраморную пыль. Получив у запыленных кроликов более тяжелый туберкулез, Бианки не присоединяется к мнению авторов, считавших мраморную или известковую пыль безвредной.

Значение пылевөго фактора в вопросе этиологии и патогенеза туберкулеза,таким образом, еще недостаточно выяснено. Имеются различные оценки действия одинаковых сортов пыли и ряд других противоречивых данных.

Вредное для здоровья действие сланцевой пыли еще мало изучено. Не выяснено, в частности, в какой степени сланцевая пыль может способствовать заболеванию туберкулезом.

Как видно из исследований С. М. Зальцмана $\left({ }^{6}\right)$ и И. Э. Клейцмана $\left({ }^{7}\right)$, частота туберкулеза среди отдельных контингентов рабочих сланцевой промышленности не отличается сколько-нибудь заметно от таковой у рабочих соответствующего возраста других отраслей промышленности. Обследовав большую группу рабочих сланцевых шахт, С. М. Зальцман обнаружил активный туберкулез легких лишь в 1,3\% случаев, причем параллелизма между туберкулезом и сланцевым силикозом им отмечено не было.

Задача настоящей экспериментальной работы заключалась в выяснении влияния вдыхания сланцевой пыли на течение туберкулеза у подопытных животных.

При постановке этой задачи мы предполагали, что сравнение результатов наших опытов с литературными данными, полученными на основании аналогических опытов с другими сортами пыли, позволит также сделать некоторые выводы о вредном для здоровья действии сланцевой пыли.

В опытах использовано 35 морских свинок, которые были разделены на пять групп. Три подопытных группы, на которых проводилось морфологическое сравнение туберкулезного процесса у запыленных и незапыленных морских свинок, состояли каждая из 8 свинок. Группа, подвергавшаяся только запылению, состояла из 5 морских свинок. В контрольной группе было 6 морских свинок.

В течение опыта определялся вес подопытных животных. Для лучшего наблюдения изменений веса опыты проводились над растущими морскими свинками, вес которых в начале опыта был $320-450$ г. Сравниваемые группы были приблизительно одинаковы по среднему весу входивших в них подопытных животных. 
Свинки трех подопытных групп были инфицированы возбудителем туберкулеза. При этом животные двух подопытных групп подвергались предварительному запылению в течение 3 месяцев. В одной инфицированной группе с предшествовавшим запылением последнее продолжалось до конца опыта. В течение всего опыта, т. е. 5 месяцев, подвергались запылению и те морские свинки, которые служили неинфицированным контролем. Одна группа инфицированных животных вообще не подвергалась запылению.

В дальнейшем в нашей работе группы морских свинок обозначены следующим образом: 1) группа только с туберкулезом, 2) группа с туберкулезом и продолжающимся запылением, 3) группа с туберкулезом и прерванным запылением, 4) группа запыленных неинфицированных животных и 5) контрольная группа.

По истечении двух месяцев после инфицирования морские свинки умерщвлялись затылочным ударом. Продолжительность наблюдения во всех группах составляла 5 месяцев.

Для оценки изменений веса время наблюдения во-всех группах было разделено на две части: а) первые три месяца (предшествовавший инфицированию период трех туберкулезных групп) и б) два последних месяца (последовавший после инфицирования период).

Для инфицирования морских свинок применялся слабой вирулентности возбудитель человеческого туберкулезного штамма $\mathrm{H}_{37} \mathrm{Rv}$. Қаждой свинке вводилось подкожно в область паха $0,2 \mathrm{~cm}^{3}$ взвеси, что составляло 300 миллионов туберкулезных палочек.

Запыление морских свинок проводилось в соответствующей динамической пылевой камере, ежедневно (исключая выходные дни) по 4 часа. Концентрация сланцевой пыли в камере была $350 \mathrm{mr} / \mathrm{m}^{3}$. По данным анализа, использованная для опытов сланцевая пыль содержала органнческих веществ $37,9 \%$ и неорганических веществ $62,1 \%$. Пыль содержала $5,8 \%$ свободной двуокиси кремния и $14,8 \%$ связанной и свободной двуокиси кремния вместе взятых.

По сравнению с контрольными животными, в поведении и общем состоянии подопытных животных не отмечалось заметных отклонений. Во всех группах в продолжение всего опыта имел место значительный прирост веса.

В течение 5 месяцев средний вес морских свинок контрольной группы и группы только с запылением увеличился почти одинаково (на 258 и 264 г). В сравнении с контрольной группой, в течение первых 3 месяцев не наблюдалось также существенных различий в приросте веса у морских свинок тех двух групп, которые подвергались запылению до инфицирования. Это является подтверждением того, что вдыхание сланцевой пыли не влияло на прирост веса растущих морских свинок.

В двух группах, где на фоне запыления развивался туберкулезный процесс, после инфицирования наблюдалась различная интенсивность прироста веса по сравнению с периодом, предшествовавшим инфицированию. После инфицирования морских свинок прирост веса у них замедлился, отставая от прироста веса контрольной группы и группы запыленных неинфицированных животных. Следует считать, что замедление прироста веса у морских свинок было связано с развитием туберкулезного процесса.

Сильнее всего замедлялся прирост веса после инфицирования у морских свинок в группе только с туберкулезом. Это наблюдение следует расценивать с известной критикой, так как уже в предшествовавшем инфицированию периоде, когда животные этой группы находились в одинаковых условиях с контрольными животными, прирост их веса в некото- 
рой степени отставал от такового у животных других групп. Очевидно, среди морских свинок подопытной группы только с туберкулезом имелись животные, прирост веса которых с самого начала по каким-то нам неизвестным причинам был слабее.

При вскрытии морских свинок у части инфицированных животных было обнаружено изъявление в месте введения культуры. У всех туберкулезных морских свинок в области введения культуры имелись подкожные некротические очаги, напоминавшие абсцессы. Паховые лимфоузлы у них были, как правило, увеличены. В более крупных узлах находились абсцедирующие очаги распада, занимавшие до половины объема лимфоузла. Увеличены и уплотнены были также ретроперитонеальные, мезентериальные и медиастинальные лимфатические узлы, содержавшие светло-желтые очажки.

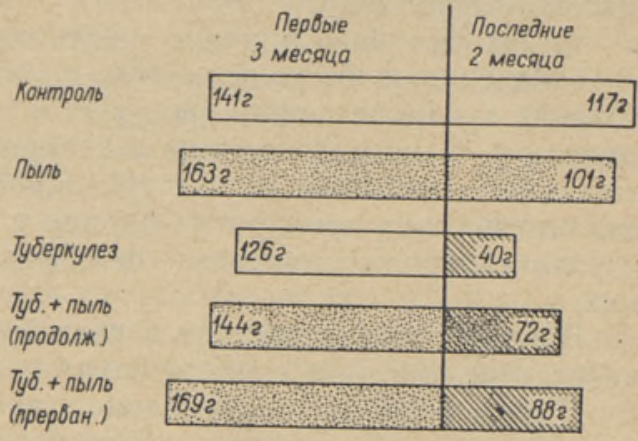

Запыление

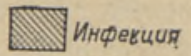

Прирост веса морских свинок по группам

В группе только с запылением

на внешней поверхности легких отмечались неравномерно распределенные и местами трудно обнаруживаемые неопределенно отграниченные небольшие пятна темно-серой пигментации. На поверхности разреза легких этих пятен было меньше. В группе только инфицированных незапыленных свинок под плеврой и на разрезе имелись редко расположенные.светлосерые узелки размером до 1 мм. Кроме последних, попадались более крупные (2-3 мм в поперечнике) плотные светло-серые узелки с центрами желтоватого оттенка.

В тех группах, где туберкулезная инфекция сочеталась с вдыханием пыли, в легких обнаруживались как пятна темно-серой пигментации, так и светло-серые узелки и более крупные плотные узелки, наблюдавшиеся в группе незапыленных туберкулезных животных.

Макроскопическое исследование легких не дало возможности обнаружить существенных групповых различий в части туберкулезных измене-
ний легких.

У туберкулезных морских свинок в печени обнаруживались светлосерые или желтовато-серые редко расположенные очажки размером 0,5-1,0 мм. В сравнении с контрольными животными селезенка у этих свинок была увеличена в незначительной степени, величина фолликулов была неравномерной. Некоторые более крупные фолликулы имели жел-
товатый центр.

Для сравнительного гистологического исследования туберкулезного процесса во всех группах были взяты кусочки ткани из легких, из трахеобронхиальных лимфатических узлов, из печени и селезенки. Гистологические срезы, изготовленные целлоидиновым методом, окрашивались гематоксилин-эозином и по ван Гизону.

Микроскопическое исследование легких, печени, селезенки и лимфатических узлов показало наличие генерализованного туберкулеза в виде небольших отграниченных очагов или бугорков, которые образовались в органах морских свинок в течение 2 месяцев после инфицирования. Гистологически туберкулезный процесс характеризовался продуктивно-фиброзными бугорками с незначительным некрозом. 
Можно считать, что такая форма туберкулеза является вполне подходящей для выяснения значения пылевого фактора. При бурно протекающем туберкулезном процессе инфекция приобрела бы настолько доминирующее значение, что это могло бы скрыть проявление слабо влияющего пылевого фактора.

Чтобы выяснить влияние вдыхания сланцевой пыли на туберкулез морских свинок, было проведено сравнительное микроскопическое исследование туберкулезного процесса в группах инфицированных морских свинок, т. е. морских свинок с туберкулезом, с туберкулезом и продолжающимся запылением и с туберкулезом и прерванным запылением. В гистологических препаратах наряду с величиной и количеством бугорков изучались пролиферативные, фибротические и альтеративные процессы в них.

В легких обнаруживалось сравнительно мало выраженных бугорков, вследствие чего они в части случаев не попадали в гистологические срезы. Таким образом, сравнивание характера бугорков различных групп происходило на основании срезов из трахео-бронхиальных лимфатических узлов, селезенки и печени.

Некротический процесс обнаруживался в бугорках редко. В отношении интенсивности некротического компонента в инфицированных группах различий не обнаружено.

Пролиферативный компонент туберкулезного процесса был хорошо выражен во всех туберкулезных группах, в частности в трахео-бронхиальных узлах и в селезенке. Пролиферативная реакция в бугорках, обнаруженных в печени, была во всех группах заметно слабее. В группе без запыления пролиферация в бугорках селезенки и лимфатических узлов была выражена несколько сильнее, чем у морских свинок, у которых туберкулез комбинировался с запылением легких. Это различие было небольшим и могло носить случайный характер. Пролиферативный компонент в группе незапыленных туберкулезных животных мог сильнее бросаться в глаза еще и потому, что фибротизация бугорков наблюдалась в несколько более слабой форме.

В бугорках был также хорошо выражен фиброз, который в бугорках селезенки и трахео-бронхиальных узлов был сильнее, чем в бугорках печени.

Склонность к фиброзу бугорков трахео-бронхиальных лимфоузлов и селезенки можно считать несколько выраженнее у свинок, у которых туберкулез сочетался с вдыханием сланцевой пыли. Может создаться впечатление, что сланцевая пыль могла способствовать фибротизации. С другой стороны, мы можем, однако, полагать, что у свинок группы только с туберкулезом общее состояние было по каким-то причинам хуже (прирост веса был также меньше), вследствие чего фиброз бугорков проявлялся в более слабой степени.

Мы склонны считать, что несколько больший прирост веса и незначительное улучшение процесса заживления (фиброз), которые отчасти отмечались в группах, где комбинировался туберкулез с запылением, нельзя относить за счет вдыхания сланцевой пыли. Конечно, не исключена возможность, что действие сланцевой пыли повышало защитные функции ретикуло-эндотелиальной системы, в результате чего процесс заживления мог усилиться.

Большее значение имеет вытекающий из опытов вывод, что продолжавшееся в течение трех и пяти месяцев запыление сланцевой пылью не вызвало в морфологической картине генерализованного туберкулезного процесса у морских свинок заметного сдвига в сторону неблагоприятного течения болезни. 
Мы не считаем сланцевую пыль безопасной или безразличной для организма. Продолжительное вдыхание сланцевой пыли, содержащей соединения силиция, несомненно оказывает влияние на организм. Исследования материала вскрытий рабочих сланцевой промышленности указывают на медленное развитие слабо выраженных силикотических изменений, вызванных сланцевой пылью (Кюнг $\left.\left({ }^{8}\right)\right)$. Следует считать, что в условиях наших непродолжительных опытов вдыхание сланцевой пыли не смогло настолько повлиять на общее состояние организма морских свинок, чтобы это проявилось в значительных сдвигах в морфологической картине туберкулезного процесса.

Опираясь на опубликованные в литературе данные, полученные на основании аналогичных опытов с другими сортами пыли, можно сделать вывод, что в условиях наших опытов отсутствие морфологических сдвигов, указывающих на менее благоприятное течение туберкулезного процесса, могло зависеть от относительно слабого вредного влияния сланцевой пыли на организм.

В вопросе о влиянии производственной пыли на возникновение и течение туберкулеза легких большую роль играет характер вдыхаемой пыли. По данным И. И. Мошковского $\left({ }^{9}\right)$, в угольных шахтах Донбасса заболеваемость туберкулезом низка и не превышает соответствующих показателей среди остального населения. Н. А. Вигдорчик $\left({ }^{1}\right)$ утверждает, что свободная от кварца угольная пыль не способствует заболеванию туберкулезом. По данным А. В. Гринберга $\left({ }^{3}\right)$, при апатитозе, который, как известно, возникает от действия свободной от кварца пыли, редко наблюдается сочетание с туберкулезом. В то же время установлено, что кварцевая пыль и все сорта пыли, содержащие значительные количества кварца, способствуют возникновению и прогрессированию туберкулеза.

Для дальнейшего выяснения затронутой проблемы необходимо провести еще ряд исследований, в частности следует провести более длительные опыты, чтобы выяснить влияние далеко развившихся пневмокониотических изменений на течение туберкулеза. Некоторые литературные данные показывают, что начальные или слабо выраженные пневмокониотические изменения обычно не оказывают заметного активизирующего действия на туберкулезный процесс легких.

На основании проведенных опытов можно сделать следующие выводы:

1. Запыление сланцевой пылью продолжительностью в три и пять месяцев не вызвало у морских свинок изменений в морфологической картине генерализованного туберкулезного процесса, которые указывали бы на менее благоприятное течение болезни.

2. У морских свинок, инфицированных возбудителем туберкулеза, наблюдалась значительная задержка прироста веса. Однако вдыхание сланцевой пыли не влияло на прирост веса молодых морских свинок.

3. Опираясь на данные, полученные в результате наших опытов, можно считать вероятным, что вдыхание сланцевой пыли, имеющей лишь слабо выраженное вредное действие на организм, не оказывает такого влияния на общее состояние организма, которое приводило бы к заметным сдвигам морфологической картины туберкулезного процесса. Для окончательного выяснения этого вопроса следует провести более широкие исследования.

\section{ЛИТЕРАТУРА}

1. Вигд д р qи к Н. А., Учение о силикозе. Медгиз, 1954.

2. Ге н ки н С. М., Клиника силикоза. М., 1948.

3. Гринберг А. В., О развитии пневмокониоза от вдыхания апатитовой пыли. Вестник рентгенологии и радиологии, 1955 , № 2, стр. $75-80$. 
4. Д аль М. К., Характеристика туберкулеза при экспериментальном силикозе. Сб. Промышленная пыль и борьба с ней, ч. II, Л., 1934, стр. 97-108.

5. Д ви жков П. П., К патологической анатомии силикоза. Сб. Борьба с силикозом, ч. I, M., 1953, стр. $244-283$.

6. 3 а льц м а н С. М., Состояние органов грудной клетки у рабочих сланцевых шахт на основании клинико-рентгенологических исследований. Вопросы гигиены труда в сланцевой промышленности Эстонской ССР, сб. II, Таллин, 1955, стр. $129-141$

7. Клейц м а н И. Э., О заболеваемости рабочих комбината «Кивиыли» легочным туберкулезом. Тезисы докладов IV научной сессии по вопросам гигиены труда в сланцевой промышленности ЭССР, Кохтла-Ярве, 1954, стр. 32-33.

8. К юн г В. А., О сланцевом силикозе у рабочих сланцевого бассейна Эстонской ССР. Изв. АН Эстонской ССР, т. IV, 1955, № 2, стр. 291-299.

9. Мошковски й И. И., Туберкулез и пневмокониоз среди подземных рабочих. Медгиз, 1941.

10. Пик Ц. Д., Силикоз и его профилактика в горнорудной промышленности. Медгиз, 1949.

11. Пожариски й Ф. И., Толгская М. С., Шилов а А. П., Патологическая анатомия силикоза. Архив патологии, 1950, № 2, стр. 23-32.

12. С е ров С. Ф., Материалы к патологической анатомии силикоза, осложненного туберкулезом. Здравоохранение Казахстана, 1954, № 9, стр. 19-29.

13. С оркин И. Э., Работы Гарднера о влиянии вдыхания пыли на течение экспериментального туберкулеза. Борьба с туберкулезом, 1933, № 1, стр. 182-184.

14. B i a n c hi, G., La Medicina del Lavoro, 1928, no. 8. - Реферат: Гигиена, безопасность и патология труда, 1929, № 2, стр. 127-128.

15. Böhme, A., Die Staublunge der Bergarbeiter besonders in ihrer Beziehung zur Tuberkulose. Klinische Wochenschrift, 1926, Nr. 27, S. 1209-1213.

16. Jöt te n, K. W., Kortma n n, Th., Gewerbestaub und Lungentuberkulose, Zweiter Teil, Berlin, 1929. - Рецензия: Гигиена, безопасность и патология труда, 1931, № $10 / 11$, стр. 170 .

Институт өкспериментальной и клинической циедицины Аккадемии наук Эстонской ССР
Поступила в редакцию 8 VI 1956

\title{
PÕLEVKIVITOLMU INHALATSIOONI MÕJUST EKSPERIMENTAALSE TUBERKULOOSI KULGEMISELE
}

\author{
V. KONG, \\ meditsiiniteaduste kandidaat \\ P. BOGOVSKI, \\ meditsiiniteaduste kandidaat
}

H. JÅNES

\section{Resümee}

Tööstusliku tolmu ja kopsutuberkuloosi vastastikuse seose küsimus on üheks komplitseeritumaks kutsehaiguste valdkonnas. Kirjandus sissehingatavate tööstuslike tolmude ja nende poolt põhjustatud pneumoskleroosi mõjust kopsutuberkuloosi tekkele ja kulgemisele sisaldab lahkuminevaid ning üksteisele vasturääkivaid andmeid. Tolmufaktori osatähtsust kopsutuberkuloosi etioloogias ja patogeneesis on hinnatud mitmeti - nii tuberkuloosset protsessi soodustava kui ka selle arenemist pidurdava kaastegurina.

Selgitamata on põlevkivitolmu kui väliskeskkonna teguri mõju kopsutuberkuloosile. Andmed põlevkivitööliste haigestumise kohta tuberkuloosi on puudulikud ning ei luba teha järeldusi tööstusliku tolmu sissehingamise ja tuberkuloosse protsessi vastastikuse seose küsimuses. 
Töö sihiks oli selgitada põlevkivitolmu inhalatsiooni mõju merisigadel tekitatud tuberkuloosi kulgemisele. Kasvuealisi merisigu, keda eelnevalt 3 kuu kestel (4 tundi päevas) hoiti vastavas põlevkivitolmu sisaldavas tolmutamiskambris (tolmu kontsentratsioon õhus $350 \mathrm{mg} / \mathrm{m}^{3}$ ), infitseeriti tuberkuloosiga. Osa infitseeritud loomade puhul jätkati nende tolmutamist. Merisigade infitseerimiseks kasutati nõrga virulentsusega inimesetuberkuloosi tekitaja tüve $\mathrm{H}_{37} \mathrm{Rv}$. Kaks kuud pärast infitseerimist leiti merisigade elundites väga vähese nekroosiga produktiivfibroosseid tuberkuleid. Võrdlusloomade hulgas oli ainult infitseeritud ja ainult tolmutatud merisigu.

Kaalu juurdekasv vähenes märgatavalt nendel merisigadel, keda infitseeriti tuberkuloositekitajatega. Seevastu ei mõjustanud põlevkivitolmu sissehingamine kasvuealiste merisigade kaalu juurdekasvu.

Kolm ja viis kuud kestnud tolmutamine põlevkivitolmuga ei põhjustanud merisigadel generaliseerunud tuberkuloosse protsessi morfoloogilises pildis haiguse ebasoodsamale kulgemisele osutavaid tunnuseid. Viimaste puudumine osutab põlevkivitolmu suhteliselt nõrgale organismi kahjustavale toimele. Rakendatud katsetingimustes ei mõjustanud põlevkivitolmu sissehingamine seevõrd organismi üldseisundit, et see oleks tunduvalt muutnud tuberkuloosse protsessi morfoloogilist pilti. Küsimuse lõplikuks selgitamiseks on vaja teostada ulatuslikumaid (pikema katsekestusega) uurimisi.

Eesti NSV Teaduste Akadeemia

Eksperimentaalse ja Kliinilise Meditsiini Instituut

Saabus toimetusse

8. VI 1956

\title{
UBER DIE WIRKUNG DES BRENNSCHIEFERSTAUBES AUF DEN VERLAUF DER EXPERIMENTELLEN TUBBERULOSE
}

\author{
W. KUNG
}

\section{P. BOGOWSKI}

\section{H. JANES}

\section{Zusammenfassung}

Die Wechselbeziehungen des gewerblichen Staubes und der Lungentuberkulose werden als eine der kompliziertesten Fragen auf dem Gebiete der Gewerbekrankheiten angesehen. Die Literaturangaben über die Wirkung des eingeatmeten gewerblichen Staubes und der vom letzteren verursachten Pneumosklerose auf die Entstehung und den Verlauf der Lungentuberkulose enthalten verschiedene, oft sogar einander widersprechende Meinungen. Die Bedeutung des Staubes in der Ätiologie und Pathogenese der Lungentuberkulose hat man verschiedenartig beurteilt _- sowohl als einen den tuberkulösen Prozess fördernden wie auch seine Entwicklung hemmenden Faktor.

Die Wirkung des Brennschieferstaubes auf die Lungentuberkulose ist ungeklärt. Die Angaben über die Morbidität der Brennschieferarbeiter an Tuberkulose sind unzureichend. Deshalb können auch keine Folgerungen gemacht werden über die Wechselbeziehungen zwischen der Einatmung des Brennschieferstaubes und der Tuberkulose. 
Aufgabe der vorliegenden Untersuchung war es, die Wirkung der Inhalation des Brennschieferstaubes auf den Verlauf der Tuberkulose bei den Meerschweinchen aufzuklären. Wachsende Meerschweinchen, die vorher während 3 Monaten (4 Stunden täglich) in einer speziellen Bestäubungskammer verblieben (Konzentration des Brennschieferstaubes $350 \mathrm{mg} / \mathrm{m}^{3}$ ), wurden mit einer Tuberkulosekultur infiziert. Ein Teil der infizierten Versuchstiere wurde noch weiter in der Kammer gehalten. Zum Infizieren der Meerschweinchen wurde der Stamm $\mathrm{H}_{37} \mathrm{Rv}$ verwendet. Zwei Monate nach der Inoculation wurden in den Organen der Meerschweinchen produktiv-fibröse Tuberkeln mit sehr geringen nekrotischen Veränderungen festgestellt. Als Kontrolltiere wurden sowohl nur tuberkulöse als auch nur bestäubte Meerschweinchen untersucht.

Eine bedeutsame Hemmung des Zuwachses an Körpergewicht fand man bei den Meerschweinchen, die mit Tuberkuloseerregern infiziert wurden. Dagegen beeinflusste die Einatmung des Brennschieferstaubes keineswegs den Zuwachs an Körpergewicht der wachsenden Meerschweinchen.

Die fünf und drei Monate lange Einwirkung des Brennschieferstaubes verursachte im morphologischen Bilde der generalisierten Tuberkulose bei den Meerschweinchen keinerlei auf einen ungünstigeren Verlauf hinweisende Veränderungen. Dies deutet hin auf eine verhältnismässig geringe schädliche Wirkung des Brennschieferstaubes auf den Organismus. Um die Frage endgültig zu lösen, ist es nötig, umfassendere Untersuchungen (mit längerer Versuchsdauer) durchzuführen.

Institut für experimentelle und klinische Medizin der Akademie der Wissenschaften der Estnischen SSR
Eingegangen am 8. Juni 1956 